\title{
Feeding in the first six months of life is associated with the probability of having bronchiolitis: a cohort study in Spain
}

Inés Gómez-Acebo ${ }^{1,2^{*}+} \mathbb{D}$, Carolina Lechosa-Muñiz ${ }^{3+}$, María Paz-Zulueta', Trinidad Dierssen Sotos ${ }^{1,2}$, Jéssica Alonso-Molero', Javier Llorca ${ }^{2,4+}$ and María J. Cabero-Perez ${ }^{1,3+}$

\begin{abstract}
Background: Breastfeeding is associated with lower incidence and severity of lower respiratory tract disease. However, little is known about the relationship between feeding type and breastfeeding duration with bronchiolitis in a child's first year.

Methods: A prospective cohort study of 969 newborn babies were followed-up for 12 months to determine breastfeeding duration, feeding type, feeding trajectory, and bronchiolitis episodes at Marqués de Valdecilla University Hospital, Spain in 2018. Type of feeding was recorded by interviewing mothers at the time of hospital discharge and at 2, 4, 6, 9 and 12 months of life, in three categories: breastfeeding, mixed feeding and infant formula. Type of feeding at hospital discharge refers to feeding from birth to discharge. In any other times studied, it refers to feeding in the last $24 \mathrm{~h}$. The association between the feeding type and bronchiolitis was analysed using logistic regression. Poisson regression was used to evaluate the association between feeding type and the number of bronchiolitis episodes with Kaplan-Meier estimators presenting the cumulative probability of suffering bronchiolitis. The results were adjusted for mother and child characteristics.
\end{abstract}

Results: Our data shows exclusive breastfeeding and mixed breastfeeding reduce the number of episodes of bronchiolitis. Regarding feeding at 4 months, exclusive breastfeeding reduced by $41 \%$ the number of episodes of bronchiolitis (adjusted incidence Ratio (aIR) 0.59, 95\% Cl 0.46, 0.76) and mixed feeding by $37 \%$ (alR 0.63, 95\% Cl 0.47, 0.86). Moreover, changing from exclusive breastfeeding to mixed feeding increased the incidence of bronchiolitis compared with continuing exclusive breastfeeding. An early swap to mixed breastfeeding before months 2 or 4 , was associated with a reduced the number of episodes of bronchiolitis, (aIR $0.53,95 \% \mathrm{Cl} 0.39,0.73$ if introduction of mixed breastfeeding before month 2, and alR $0.61,95 \% \mathrm{Cl} 0.45,0.83$ if introduction of mixed breastfeeding before month 4), when compared with infant formula alone.

Conclusions: Any breastfeeding was associated with lower incidence of bronchiolitis and number of episodes of bronchiolitis in the first year of life. Consequently, promoting programmes facilitating exclusive or mixed breastfeeding would be a relevant measure in the prevention of bronchiolitis.

Keywords: Breastfeeding, Breastfeeding duration, Feeding type, Feeding trajectory, Bronchiolitis, Spain

\footnotetext{
* Correspondence: ines.gomez@unican.es

'Inés Gómez-Acebo and Carolina Lechosa-Muñiz shared first authorship.

†Javier Llorca and María J Cabero-Perez shared senior authorship.

${ }^{1}$ Universidad de Cantabria - IDIVAL, Santander, Spain

${ }^{2}$ CIBER Epidemiología y Salud Pública (CIBERESP), Madrid, Spain

Full list of author information is available at the end of the article
}

(c) The Author(s). 2021 Open Access This article is licensed under a Creative Commons Attribution 4.0 International License, which permits use, sharing, adaptation, distribution and reproduction in any medium or format, as long as you give appropriate credit to the original author(s) and the source, provide a link to the Creative Commons licence, and indicate if changes were made. The images or other third party material in this article are included in the article's Creative Commons licence, unless indicated otherwise in a credit line to the material. If material is not included in the article's Creative Commons licence and your intended use is not permitted by statutory regulation or exceeds the permitted use, you will need to obtain permission directly from the copyright holder. To view a copy of this licence, visit http://creativecommons.org/licenses/by/4.0/. The Creative Commons Public Domain Dedication waiver (http://creativecommons.org/publicdomain/zero/1.0/) applies to the data made available in this article, unless otherwise stated in a credit line to the data. 


\section{Background}

Acute bronchiolitis is a lower respiratory tract infection which affects children under 2 years of age, although it tends to occur in the first year of life [1]. It is usually a moderate illness, but in some infants, it can be more severe and require hospitalization. Approximately 10-15\% of children have acute bronchiolitis during the first year of life [2].

Bronchiolitis is usually caused by respiratory syncytial virus (RSV), and is associated with more than $50 \%$ of hospitalization in infants [3]. In 2015, it had been estimated that 33.1 million episodes of RSV infection, resulting in about 3.2 million hospital admissions and 59.600 in-hospital deaths, happened globally, in children younger than 4 years [4]. Furthermore, many observational studies have shown that RSV disease in childhood is associated with increased wheezing or asthma later in childhood $[2,5]$.

Some widely described factors that increase the risk of suffering from acute bronchiolitis are comorbidities such as prematurity, bronchopulmonary dysplasia, or congenital heart disease [6, 7]. Regarding socio-demographic factors, there is a relationship between the incidence of bronchiolitis and maternal youth [8,9]. Furthermore, factors related to the mother's nutritional status and her stress level are involved [10]. In addition, attendance at daycare or living with older siblings are also shown as factors that increase risk [8]. Considering external factors that can be modified in the environment of individuals, exposure to tobacco constitutes a well-established risk factor, both for the susceptibility of suffering an episode of bronchiolitis and for it to be more severe [10, 11]. Breastfeeding is associated with lower incidence and severity of lower respiratory tract disease [12-14] and several studies have confirmed that the longer the duration of breastfeeding the better the clinical outcome of the episode of bronchiolitis $[15,16]$. In this way, the World Health Organization, as well as scientific societies in America and Europe, recommends exclusive breastfeeding for the first 6 months of life [17]. However, despite the beneficial effects of breastfeeding and the recommendations of different scientific societies, in European countries exclusive breastfeeding rates reached around 56-98\% immediately after birth and drop to only $13-39 \%$ at 6 months of life [18].

Our main objective was to determine the relationship between type of feeding and duration of breastfeeding and bronchiolitis in the first year of life.

\section{Methods}

\section{Design and setting}

Prospective cohort study that includes 969 newborns recruited consecutively from January 1, 2018 to August 31, 2018, at the Marqués de Valdecilla University Hospital
(HUMV), Santander, Spain. The HUMV is a public hospital, which is implemented in the Baby-Friendly Hospital Initiative (BFHI) [19] and attends around 3000 deliveries a year. Details on design and gathering information have been published elsewhere [20]. This manuscript is a further analysis of that sample after following children for 1 year.

\section{Data collection}

Data on pregnancy, delivery, and characteristics before hospital discharge, including type of feeding at discharge, were obtained from obstetrics records. All neonates were followed-up for 12 months to determine the duration of breastfeeding and the presence of bronchiolitis. Information in the follow-up was obtained from paediatric records and via an interview with the mother at the time of hospital discharge and in each regular consultation with the paediatrician. In this regard, the childcare program of the Regional Service of Health established each child should have a paediatrician review at 2, 4, 6, 9 and 12 months of life.

Apart from the main exposure of type of feeding and the event of bronchiolitis, which are further developed, information was gathered about maternal age, educational level, occupational activity, smoking during pregnancy, duration of pregnancy, type of delivery and whether the pregnancy was single or multiple. Information about neonates included sex and birthweight, as well as conditions present at birth. Newborn attendance to childcare was obtained by interviewing the mother in each check-up at 2, 4, 6, 9 and 12 months of life. Attendance to daycare was obtained by interviewing the mother.

\section{Type of feeding: data management}

Type of feeding was recorded via interviewing mothers at the time of hospital discharge and at 2, 4, 6, 9 and 12 months of life, in three categories: breastfeeding, mixed feeding and infant formula. In this regard, type of feeding at hospital discharge is considered for infants who have been exclusively breastfed or who have received expressed breast milk from birth to discharge. In the other time points studied the type of feeding refers to the food received in the last $24 \mathrm{~h}$. Breastfeeding was considered that WHO's definition for "exclusive breastfeeding", it means that the infant receives since birth breast milk (including expressed breast milk or breast milk from a wet nurse) and allows the infant to receive oral rehydration salts, drops, syrups (vitamins, minerals, medicines), but nothing else (no other food or drink, not even water) [21]. Mixed feeding was when the infant supplemented breastfeeding with infant formula. Infant formula means exclusive formula milk. Then, 
at each time point $(2,4,6,9$ and 12 months), we identified the feeding trajectory in four categories: (1) Infant formula only (2) Previously breastfed, currently infant formula only (3) Previously exclusive breastfeeding or any breastfeeding, currently any breastfeeding (4) Exclusive breastfeeding since birth. For instance, a neonate breastfed until month three, then changed to mixed feed until month seven and then changed to formula would be classified as category 4 (breastfeeding) in month 2 , category 3 in month 4 as she/he changed from breastfeeding to mixed, category 3 in month 6 as she/he continued with mixed feed and category 2 in month nine. Figure 1 shows an example of the evolution in the type of breastfeeding from 2 months to 4 months in six different women as a function of the mother's responses to the twoand four-month interviews.

\section{Bronchiolitis: data management}

Diagnosis of bronchiolitis was assessed from paediatric records and interviews with the mother. For this analysis we classified bronchiolitis in three ways: (1) as dichotomic variable (the neonate had bronchiolitis or not), (2) as number of episodes of bronchiolitis in the follow-up, (3) as the period bronchiolitis occurred (cumulative number of episodes of bronchiolitis from birth to 12 th month, from 2 nd to 12 th month, from 4th to 12th month, and from 6th to 12th month). This last classification allowed us to analyse type of feeding at specific time, say 2nd month, bronchiolitis association without risking a reverse causation bias.

\section{Statistical analysis}

Descriptive results are presented as number (percentage) or mean \pm standard deviation.

The association between the type of feeding and the presence of bronchiolitis was analysed using logistic regression. The results, adjusted for maternal smoking, maternal occupational status, twin pregnancy, gestation length, birth order, attending daycare and months at which the neonate began kindergarten, are presented as adjusted Odds Ratio (aOR) with 95\% confidence intervals $(95 \% \mathrm{CI})$. The association between type of feeding and the number of episodes of bronchiolitis was assessed by Poisson regression and the results were presented as adjusted incidence rate Ratio (aIR) with 95\% confidence intervals.

The cumulative probability of suffering bronchiolitis is presented using Kaplan-Meier estimators. For this analysis, the event was defined as the first diagnosis of bronchiolitis and infants were censored if they did not have bronchiolitis at 12 months of life. A complementary Kaplan-Meier estimator was carried out for repeated events; that is, children were followed for 12 months and each episode of bronchiolitis was considered an event.

All statistical analyses were performed with the Stata 16/SE software (Stata Co., College Station, Tx, US).

\section{Ethical considerations}

This project was approved by the Ethics Committee for Clinical Research of Cantabria on 21 July 2017, reference number 2017.142. During the hospital stay after delivery, mothers were informed of the existence of the study and

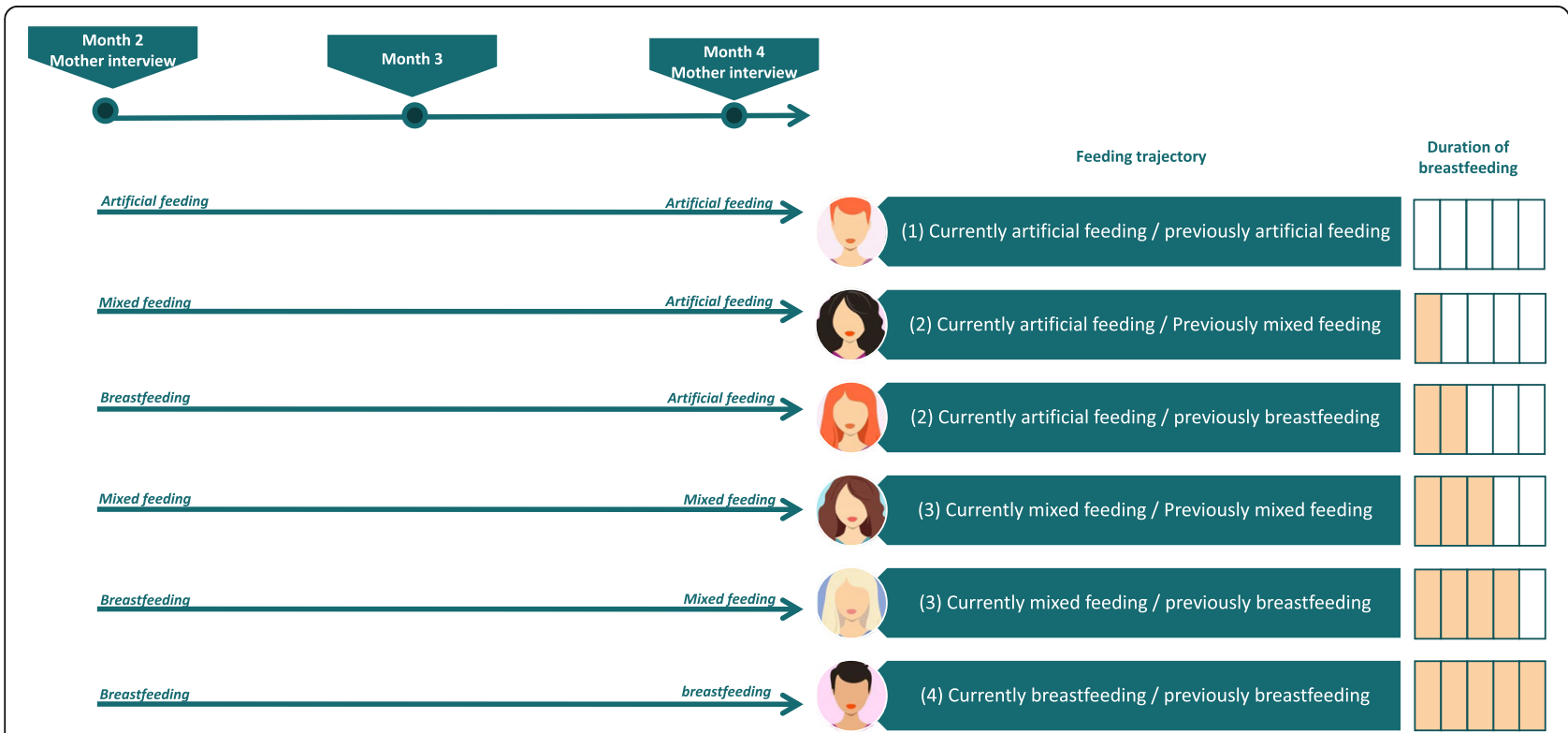

Fig. 1 Example of the evolution in the type of breastfeeding in six different women based on the mother's responses to the two- and four-month interviews 
they were requested to sign the informed consent form to participate in the study. The project was carried out according to the Spanish laws on biomedical research, the European Union regulations on the protection of natural persons with regard to the processing of personal data and the Declaration of Helsinki on ethical principles for medical research involving human subjects.

\section{Results}

The descriptive data of the cohort were previously published [22]. The initial sample was 969 newborns included in the study at birth. Sixty-two children were excluded because it was unknown whether they had bronchiolitis. Finally, 907 newborns out of 888 pregnancies were included in the analysis and 882 children (91\%) were followed up to 12 months.

The main characteristics of mothers and children in this cohort are shown in Table 1. Mothers were $33.7 \pm$ 5.2 years old on average and $37 \%$ of mothers $(N=332)$ had university studies and approximately $70 \%$ worked outside home. Additionally, around $87 \%$ of mothers did not smoke during pregnancy. About half of children were females, $5.5 \%$ of children were premature, $24 \%$ were delivered via Caesarean section and $8 \%$ weighed less than $2500 \mathrm{~g}$ at birth.

\section{Probability of a child suffering bronchiolitis}

Over the 12 months, we detected 234 episodes of bronchiolitis in 907 children. About 6\% of the children had an episode of bronchiolitis by the 6th month of life and the percentage increased to 16,23 , and $26 \%$ at 8,10 , and 12 months after birth, respectively. Figure 2 displays Kaplan-Meier estimates of the probability of suffering at least one bronchiolitis (Fig. 2a) and the cumulative number of episodes of bronchiolitis in the first year of life (Fig. 2b).

Regarding pregnancy duration, 10 out of $20(50 \%)$ were delivered before week 34,14 out of 24 (37\%) whose gestation lasted 34-36, and 231 out of 897 (27\%) delivered at term, have had at least an episode of bronchiolitis. Differences were also observed regarding the infant's sex, $32 \%$ of male and $24 \%$ of female have had bronchiolitis. When evaluating the number of twins, we observed that 18 children (46\%) of twins compared to $27 \%$ of singleton have had bronchiolitis. Regarding daycare attendance, $40 \%(52 / 132)$ of infants attending childcare experienced bronchiolitis compared to 26\% (197/ 763) of infants who did not attending it (Table 1). Relationship between feeding and bronchiolitis.

Table 2 shows the association between feeding and risk of developing bronchiolitis in the first year of life. Regarding the type of feeding, breastfeeding at time of hospital discharge was associated with a lowering the risk of developing bronchiolitis by approximately $40 \%$ compared to infant formula (aOR 0.61; 95\% CI 0.41, 0.91 for exclusive breastfeeding and aOR $0.60,95 \% \mathrm{CI}$ 039, 0.94 for mixed feeding). Results at 2nd, 4th and 6th months were similar.

When we evaluated the change in the type of breastfeeding at 2 months after birth, we observed that not only exclusive breastfeeding but also those who had been mixed feeding was associated with $42-46 \%$ lower bronchiolitis risk compared to those who were exclusively fed with infant formula in those 2 months (aOR 0.58, 95\% CI $0.35,0.98$ for infant formula at 2 months and previously breastfeeding or mixed feeding and aOR 0.54 , 95\% CI 033, 0.89 for mixed feeding at 2 months and previously breastfeeding or mixed feeding).

Figure 3a illustrates the probability of bronchiolitis according to change in the type of feeding in the first 4 months of life. Children artificially fed at 4 months were more likely to have bronchiolitis than those exclusively or mixed breastfed at 4 months.

Regarding duration of breastfeeding, we observe that the longer the breastfeeding duration, the stronger the protection against bronchiolitis. For instance, maintaining breastfeeding for 2 months was associated with $45 \%$ lower risk of bronchiolitis compared to infant formula only (aOR 0.55 ; 95\% CI $0.38,0.81$ ). While breastfeeding for more than 6 months reduced the risk of bronchiolitis by $55 \%$ between 6 and 12 months of life compared to infant formula (aOR 0.45; 95\% CI 0.29, 0.70).

Figure 4a shows the probability of bronchiolitis according to duration of breastfeeding up to 4 months. Children who never breastfed had more bronchiolitis than those who were breastfeeding at least 4 months (24\% vs. $14 \%$ at 8 months, and $35 \%$ vs. $23 \%$ at 12 months).

\section{Breastfeeding and number of episodes of bronchiolitis}

Table 3 shows the relationship between the type of breastfeeding and the number of episodes of bronchiolitis. Results are presented as adjust Incidence Ratios (aIR).

Our data show that exclusive breastfeeding and mixed breastfeeding reduce the number of episodes of bronchiolitis when compared with infant formula. Regarding feeding at hospital discharge, exclusive breastfeeding cut down the number of episodes of bronchiolitis by $41 \%$ (aIR $0.59,95 \%$ CI $0.46,0.75$ ) and mixed feeding by $36 \%$ (aIR 0.64, 95\% CI 0.49, 0.84). Similar reductions in the number of episodes of bronchiolitis were achieved when analysing type of feeding at 2nd, 4th and 6th months.

When we evaluated the change in the type of feeding, we found that an early cessation of breastfeeding before 2nd or 4th months, was associated with a higher incidence of bronchiolitis episodes (aIR 0.79, 95\% CI 0.59, 1.06 if introduction of infant formula before 2nd month, 
Table 1 Main characteristics of participants in the study

\begin{tabular}{|c|c|c|c|c|c|c|c|c|c|}
\hline \multirow[b]{3}{*}{ Variable } & \multirow[b]{3}{*}{ Category } & \multirow{3}{*}{$\begin{array}{l}\text { Total } \\
\begin{array}{l}N=907 \\
\mathrm{~N}(\%)\end{array}\end{array}$} & \multicolumn{3}{|c|}{ Bronchiolitis } & \multirow{3}{*}{$\begin{array}{l}N=652 \\
0\end{array}$} & \multicolumn{3}{|c|}{$\begin{array}{l}\text { Number of episodes of } \\
\text { bronchiolitis }\end{array}$} \\
\hline & & & \multirow{2}{*}{$\begin{array}{l}N=652 \\
\text { No }\end{array}$} & \multirow{2}{*}{$\begin{array}{l}N=255 \\
\text { Yes }\end{array}$} & \multirow[b]{2}{*}{$\mathbf{P}$} & & \multirow{2}{*}{$\begin{array}{l}N=162 \\
1\end{array}$} & \multirow{2}{*}{$\begin{array}{l}N=93 \\
>1\end{array}$} & \multirow[b]{2}{*}{$\mathbf{p}$} \\
\hline & & & & & & & & & \\
\hline Maternal age (years) & mean $\pm s d$ & $33.7 \pm 5.2$ & $33.84(0.20)$ & $33.36(0.32)$ & 0.213 & $33.84(0.20)$ & $33.55(0.41)$ & $33.04(0.54)$ & 0.348 \\
\hline \multirow[t]{4}{*}{ Maternal educational level } & Primary studies & $215(22.7)$ & $144(72.36)$ & $55(27.64)$ & 0.643 & $144(72.36)$ & $30(15.08)$ & $25(12.56)$ & 0.290 \\
\hline & Secondary studies & $112(11.8)$ & $79(72.48)$ & $30(27.52)$ & & 79 (72.48) & $23(21.10)$ & $7(6.42)$ & \\
\hline & foundation degree & $272(28.7)$ & $180(68.97)$ & $81(31.03)$ & & $180(68.97)$ & 48 (18.39) & $33(12.64)$ & \\
\hline & University studies & $350(36.9)$ & $249(73.67)$ & $89(26.33)$ & & $249(73.67)$ & $61(18.05)$ & $28(8.28)$ & \\
\hline \multirow[t]{4}{*}{ Maternal occupation } & working & $660(69.6)$ & $451(71.36)$ & $181(28.64)$ & 0.911 & $451(71.36)$ & $121(19.15)$ & $60(9.49)$ & 0.655 \\
\hline & unemployed & $163(17.2)$ & $116(73.89)$ & $41(26.11)$ & & 116 (73.89) & $24(15.29)$ & $17(10.83)$ & \\
\hline & Inactive & $116(12.2)$ & 79 (72.48) & $30(27.52)$ & & 79 (72.48) & 15 (13.76) & $15(13.76)$ & \\
\hline & Student & $10(1.1)$ & $6(66.67)$ & $3(33.33)$ & & $6(66.67)$ & $2(22.22)$ & $1(11.11)$ & \\
\hline \multirow[t]{2}{*}{ Smoking in pregnancy } & No & $830(87.5)$ & $571(72.10)$ & $221(27.90)$ & 0.711 & $571(72.10)$ & $140(17.68)$ & $81(10.23)$ & 0.922 \\
\hline & Yes & 119 (12.5) & $81(70.43)$ & $34(29.57)$ & & $81(70.43)$ & $22(19.13)$ & $12(10.43)$ & \\
\hline Cigarettes/day & mean $\pm s d$ & & $0.12(0.01)$ & $0.13(0.02)$ & 0.712 & $0.12(0.01)$ & $0.14(0.03)$ & $0.13(0.03)$ & 0.923 \\
\hline \multirow[t]{3}{*}{ Pregnancy duration } & $<34$ weeks & $16(1.7)$ & $10(50.00)$ & $10(50.00)$ & 0.038 & $10(50.00)$ & $5(25.00)$ & $5(25.00)$ & 0.020 \\
\hline & 34-36 weeks & $36(3.8)$ & $24(63.16)$ & $14(36.84)$ & & $24(63.16)$ & $6(15.79)$ & $8(21.05)$ & \\
\hline & $\geq 37$ weeks & $897(94.5)$ & $618(72.79)$ & $231(27.21)$ & & $618(72.79)$ & $151(17.79)$ & $80(9.42)$ & \\
\hline \multirow[t]{3}{*}{ Type of delivery } & Vaginal & $653(67.4)$ & $446(73.00)$ & $165(27.00)$ & 0.062 & $446(73.00)$ & $105(17.18)$ & $60(9.82)$ & 0.216 \\
\hline & Instrumental vaginal & $80(8.3)$ & $60(78.95)$ & $16(21.05)$ & & $60(78.95)$ & $11(14.47)$ & $5(6.58)$ & \\
\hline & Caesarean section & $236(24.4)$ & $146(66.36)$ & $74(33.64)$ & & $146(66.36)$ & $46(20.91)$ & $28(12.73)$ & \\
\hline \multirow[t]{2}{*}{ Newborn gender } & Male & $490(50.6)$ & $312(68.27)$ & 145 (31.73) & 0.015 & $312(68.27)$ & $83(18.16)$ & $62(13.57)$ & 0.003 \\
\hline & female & $479(49.4)$ & $340(75.56)$ & $110(24.44)$ & & $340(75.56)$ & 79 (17.56) & $31(6.89)$ & \\
\hline \multirow[t]{2}{*}{ Sibling pregnancy } & No & 929 (95.9) & $631(72.70)$ & $237(27.30)$ & 0.010 & $631(72.70)$ & $155(17.86)$ & $82(9.45)$ & 0.001 \\
\hline & Yes & $40(4.1)$ & $21(53.85)$ & $18(46.15)$ & & $21(53.85)$ & 7 (17.95) & $11(28.21)$ & \\
\hline \multirow[t]{3}{*}{ Newborn weight } & $<2500$ & $83(8.6)$ & $54(66.67)$ & $27(33.33)$ & 0.474 & $54(66.67)$ & $15(18.52)$ & $12(14.81)$ & 0.474 \\
\hline & $2500-4000 \mathrm{~g}$ & $808(93.4)$ & $545(72.67)$ & $205(27.33)$ & & $545(72.67)$ & $130(17.33)$ & $75(10.00)$ & \\
\hline & $>4000 \mathrm{~g}$ & $78(8.1)$ & $53(69.74)$ & $23(30.26)$ & & $53(69.74)$ & $17(22.37)$ & $6(7.89)$ & \\
\hline \multirow[t]{3}{*}{ Attending daycare } & No & $763(78.7)$ & $556(73.84)$ & $197(26.16)$ & 0.006 & $556(73.84)$ & $121(16.07)$ & $76(10.09)$ & 0.015 \\
\hline & Yes & $132(13.6)$ & $79(60.31)$ & $52(39.69)$ & & $79(60.31)$ & $37(28.24)$ & $15(11.45)$ & \\
\hline & Unknown & $74(7.6)$ & $17(73.91)$ & $6(26.09)$ & & $17(73.91)$ & $4(17.39)$ & $2(8.70)$ & \\
\hline Breastfeeding duration ${ }^{a}$ (months) & mean $\pm s d$ & $5.9 \pm 5.2$ & $6.22(0.21)$ & $5.26(0.33)$ & 0.014 & $6.22(0.21)$ & $5.54(0.41)$ & $4.79(0.54)$ & 0.026 \\
\hline
\end{tabular}

${ }^{\mathrm{a}}$ Any breastfeeding

and aIR $0.83,95 \%$ CI $0.58,1.19$ if introduction of infant formula before 4th month), while changing from exclusive breastfeeding to mixed feeding had no effect on aIR.

Figure $3 \mathrm{~b}$ illustrates the probability of and the number of episodes of bronchiolitis according to change in the type of feeding in the first 4 months of life. Children with infant formula at 4 months were more likely to have bronchiolitis than those breastfed at 4 months.

On the other hand, when assessing the duration of exclusive breastfeeding in the first 2 months and the risk of recurrent bronchiolitis between 2 to 12 months of life, we observed that maintaining breastfeeding for 2 months was associated with $48 \%$ lower risk having another bronchiolitis episode (HR 0.52; 95\% CI 0.41, 0.65). A similar result was observed for those who were breastfed for at least 4 months regarding the risk of suffering one more bronchiolitis between 4 and 12 months. Likewise, maintaining exclusive breastfeeding for 6 months was associated with 50\% risk reduction between 6 and 12 months of life (HR 0.50; 95\% CI 0.37, 0.67).

Figure $4 \mathrm{~b}$ shows the probability of and the number of episodes of bronchiolitis according to duration of breastfeeding up to 4 months. In the whole cohort children, who took infant formula had a higher number of episodes of bronchiolitis at 12 months compared to those who breastfed for at least 4 months (50\% vs. $27 \%)$. 


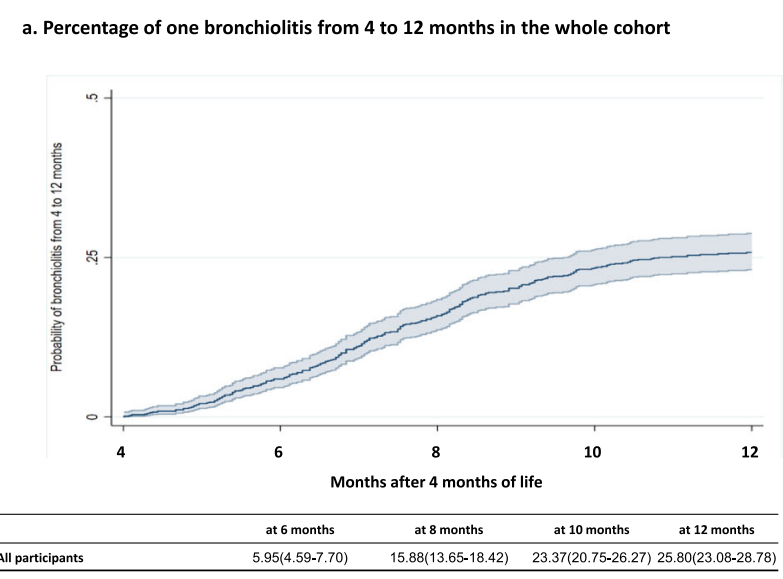

b. Percentage of more than one bronchiolitis from 4 to 12 months in the whole cohort

Note. Kaplan-Meier estimates and $95 \%$ confidence interval

Fig. 2 Bronchiolitis in the whole cohort. Kaplan Meier estimates with 95\% confidence bands

\section{Discussion}

According to our results, any breastfeeding was associated with lower risk of bronchiolitis and lower number of bronchiolitis episodes in this cohort of about one thousand neonates. Early cessation of breastfeeding before the second or fourth month of life was linked to both risk of bronchiolitis and number of bronchiolitis episodes between those babies breastfed and those fed with infant formula. Furthermore, our results showed that the duration of breastfeeding, regardless of the exclusivity of breastfeeding (breastfeeding and mixed breastfeeding) from 0 to 6 months, is a crucial factor in reducing the incidence of bronchiolitis and the number of episodes of bronchiolitis in the first year of life. This may suggest that a longer duration of breastfeeding (regardless of whether it is mixed or exclusive) could reduce the risk of bronchiolitis in the first years of life, and this also suggests that continued exposure to breastfeeding may play a significant role in preventing adverse respiratory outcomes, thus resulting in a lower medical care.

Other studies that have assessed the duration of breastfeeding have also observed a lower risk of adverse respiratory outcomes [23-26]. Lanari et al. also noted that breastfeeding, even in association with formula milk reduced the risk of hospitalization for bronchiolitis during the first year of life [27]. Other studies have also found this association. Thus, Dogaru et al., in a systematic review and meta-analysis, found that the stronger protective effect of breastfeeding was observed in the age group 0 to 2 years for both "asthma ever" and "recent asthma" events regardless of the length or exclusive breastfeeding [28]. Also in line with our findings, the study published by Davisse-Paturet found an association between duration of breastfeeding and its protective effect against bronchiolitis [29]. Our results are also supported by the study by Dekker et al., who found in a prospective cohort of 5675 children, that infant formula was associated with an increased risk of late and persistent wheezing compared to any type of breastfeeding [30]. However, other studies that have studied this relationship have failed to find any association. Thus, Leung et al. did not find an association between exclusive or partial breastfeeding for 3 months or more and hospitalization for asthma, bronchitis and bronchiolitis at age twelve [31]. Nenna et al., in their study of 213 infants hospitalized in Italy, noted that breastfeeding for more than 3 months was associated with increased risk of bronchiolitis [32]. The authors speculated that their findings could reflect the transmission of respiratory infection from mother to child during breastfeeding [32], although the authors did not discuss the possibility of reverse causality (i.e., mothers continuing breastfeeding because they were concerned about the vulnerability of their babies), which could not be ruled out in their casecontrol design. Our study, however, was designed with prospective follow-up, which allows us to properly identify that bronchiolitis episodes occurred after the feeding period we were analysing each time.

If the lower risk of bronchiolitis we have found is a true protective effect of breastfeeding observed in the first year of life, it may be due to the fact that breast milk contains substances that may have biological effects that can promote lung growth and improve lung function [33, 34]. It has been shown that breastfed children have higher lung volume at the age of 10 years and an investigation attributed this advantage to the mechanical stimulus associated with sucking chest in the early years of life [35]. In addition, the transforming growth factor (TGF) - $\beta$ contained in breast milk is inversely associated with the risk of having wheezing episodes during the first year of life [36]. On the other hand, breast milk 


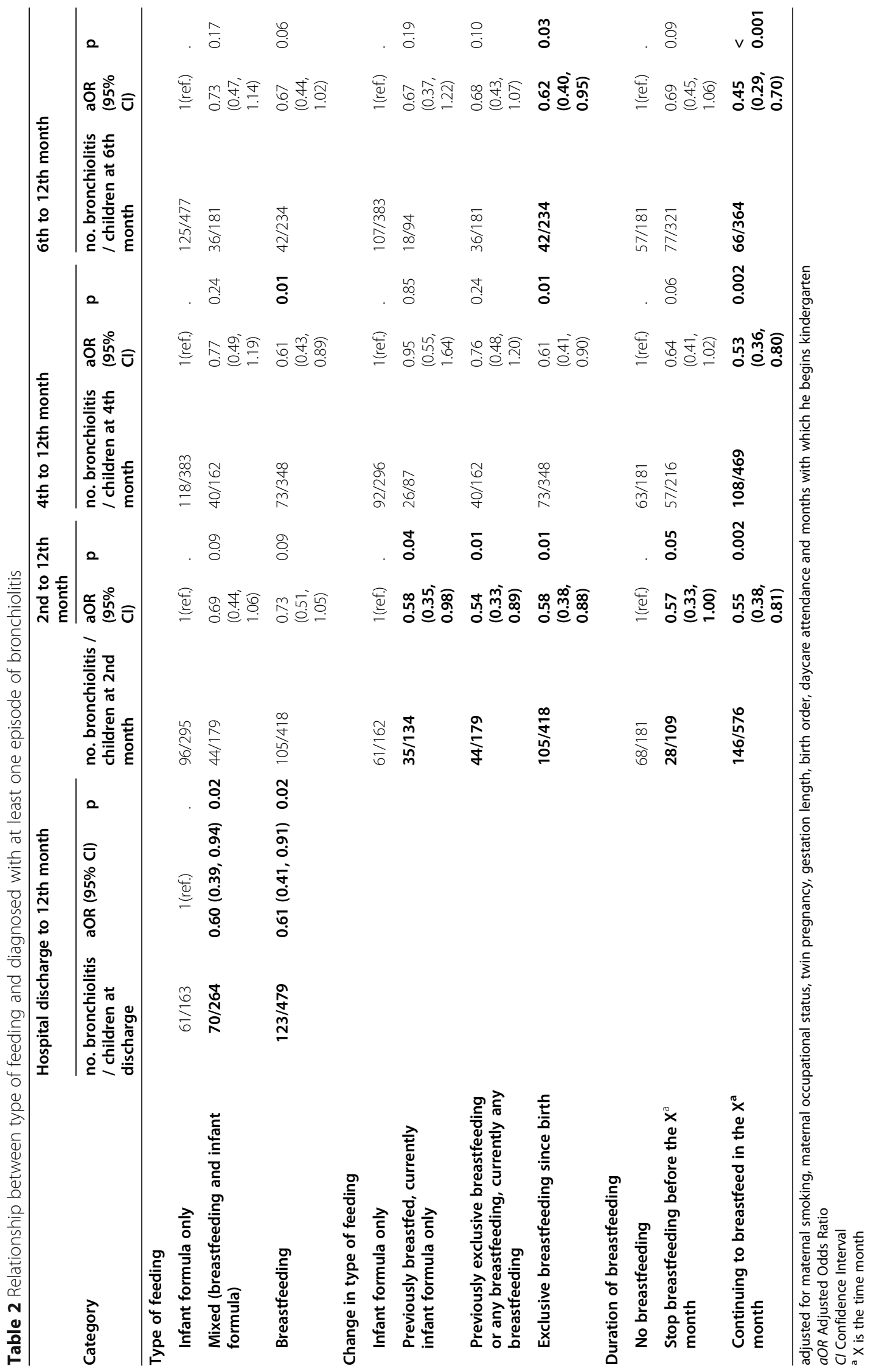




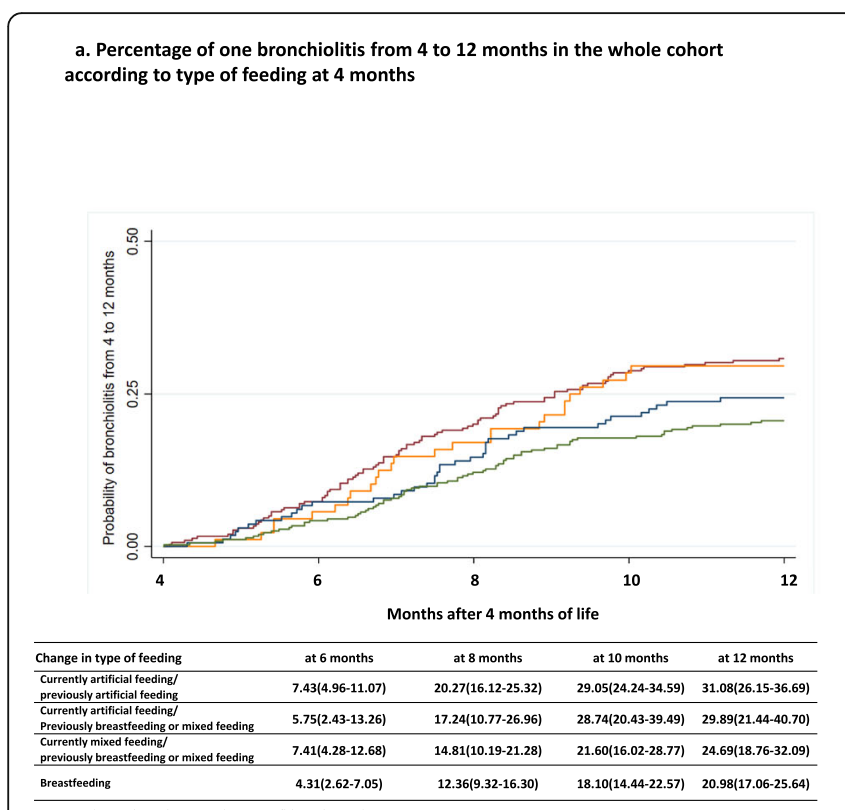

b. Percentage of more than one bronchiolitis from 4 to 12 months in the whole cohort according to type of feeding at 4 months

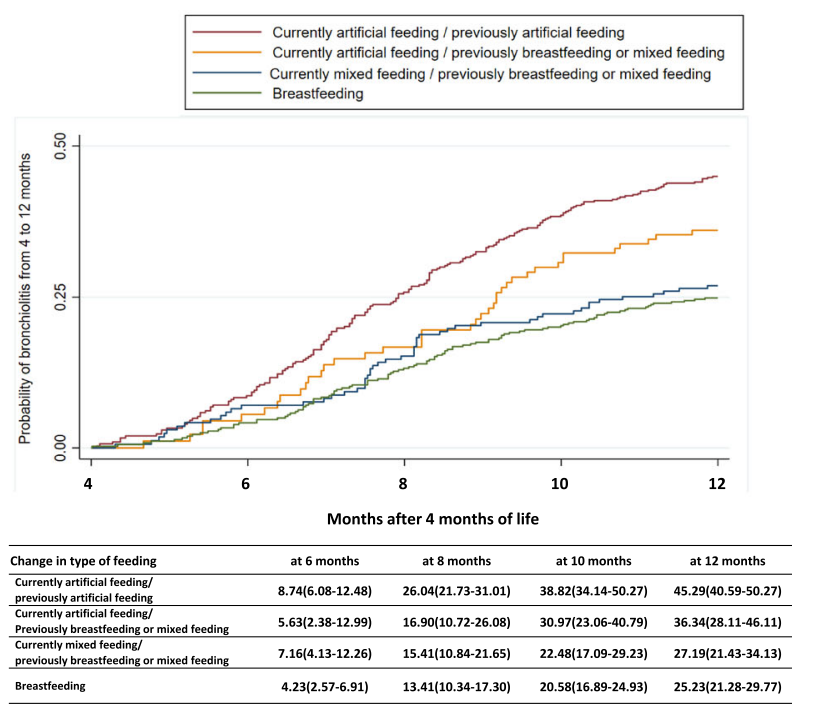

Fig. 3 Probability of bronchiolitis (a) and number of episodes of bronchiolitis (b) from 4 to 12 months in the whole cohort according to duration of breastfeeding at 4 months

contains numerous anti-inflammatory and immunological agents [37]. This makes breastfed infants perform superior functions than formula-fed infants [38]. In addition, breastfed infants have fewer respiratory tract infections in the first years of life [36] and infections of the lower respiratory tract is the main established risk factor for bronchiolitis. In this regard, Li et al. found that the mothers of infants with bronchiolitis had lower IgG concentration in breast milk. IgG from breast milk could be absorbed by infants, which could play an important role in resistance to bronchiolitis [39].

The main strength of our study is that a homogeneous prospective follow-up of women and children has been carried out in a single centre committed to breastfeeding practices with a relatively large number of participants. In addition, the children's medical records have been

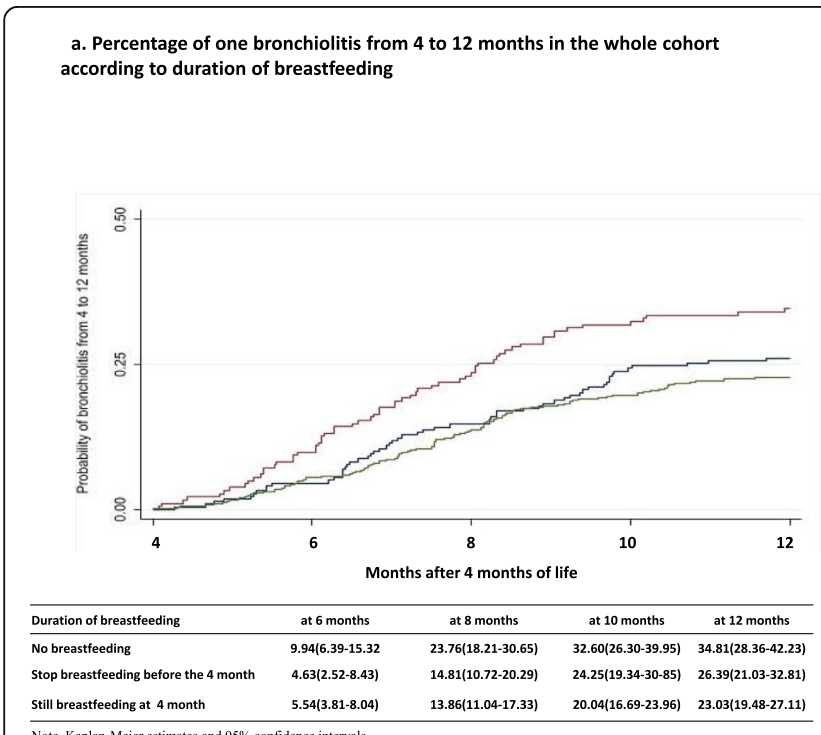

b. Percentage of more than one bronchiolitis from 4 to 12 months in the whole cohort according to duration of breastfeeding
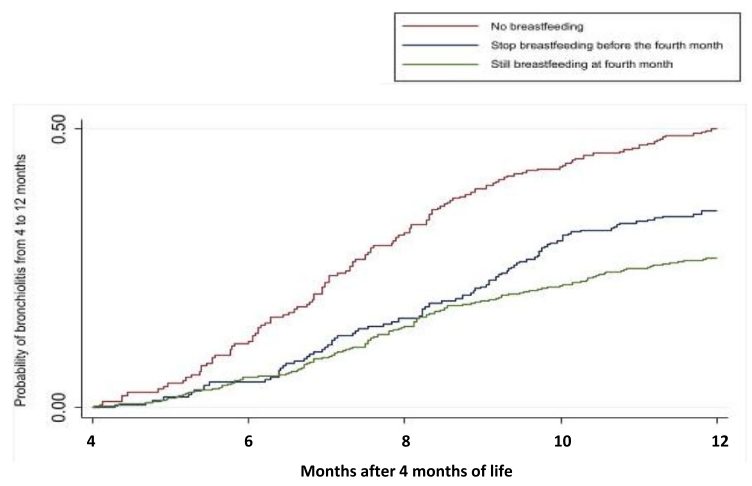

\begin{tabular}{lcccc}
\hline Duration of breastffeeding & at 6 months & at 8 months & at 10 months & at 12 months \\
\hline No breastfeeding & $11.97(8.13-17.46)$ & $31.43(25.73-38.03)$ & $43.22(37.26-49.70)$ & $50.02(44.12-56.24)$ \\
Stop breastffeeding before the 4 month & $4.54(2.47-8.27)$ & $16.18(12.05-21.53)$ & $30.07(24.88-36.05)$ & $35.38(30.00-41.40)$ \\
Still breastffeeding at 4 month & $5.40(3.71-7.83)$ & $14.62(11.83-18.01)$ & $21.96(18.67-25.73)$ & $26.98(23.47-30.90)$ \\
\hline
\end{tabular}

Fig. 4 Probability of bronchiolitis (a) and number of episodes of bronchiolitis (b) from 4 to 12 months in the whole cohort according to type of feeding at 4 months 


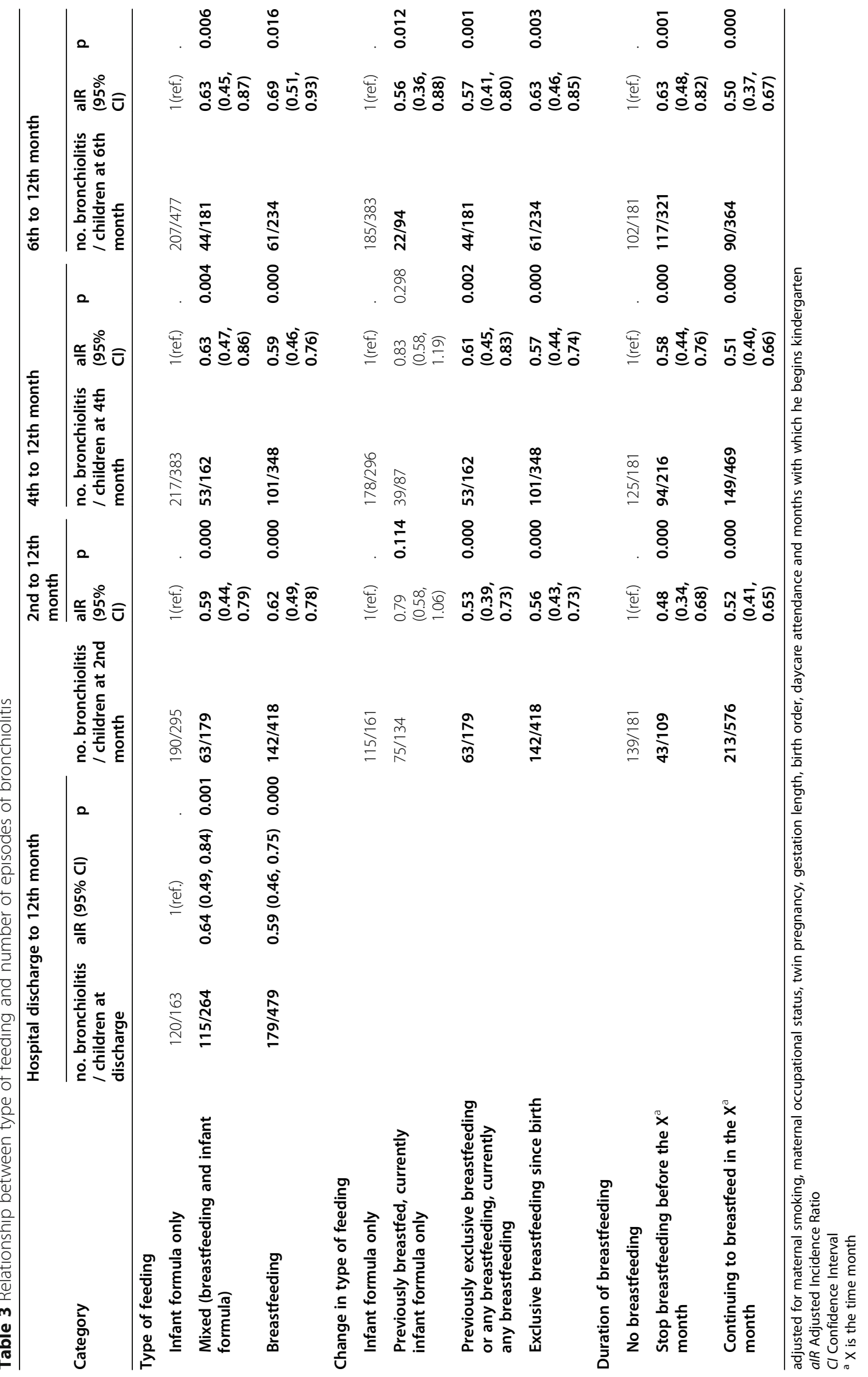


reviewed to objectively know the presence of bronchiolitis and the date of the bronchiolitis, thus avoiding the parents' recall bias.

However, our study also has some limitations. First, although the size is close to 1000 children, some categories of the analysis have few participants, for example, breastfeeding from the 6th month, this means that we could not study the effect of continued breastfeeding. Harvey et al. in a recent study, observed that breastfeeding for more than 6 months versus "never" was associated with decreased risk of infant wheezing [23]. Second, as breastfeeding information is self-reported, we could have made a reporting bias, since women could have informed in accordance with social expectations and not according to their actual practice.

\section{Conclusions}

The type of breastfeeding used in the first 6 months of life and the duration of breastfeeding impacts the probability of having one, or more than one bronchiolitis in the first year of life. Breastfeeding and mixed feeding, compared to infant formula only, protects against the development of bronchiolitis and the number of episodes of bronchiolitis in the first year of life. Therefore, promoting exclusive or mixed breastfeeding is an easy to implement and economical measure that would be effective in preventing bronchiolitis in infancy.

\section{Abbreviations \\ alR: Adjusted Incidence Ratio; aOR: Adjusted Odds Ratio; Cl: Confidence Interval; HUMV: Hospital Universitario Marqués de Valdecilla; SD: Standard deviation}

\section{Acknowledgements}

Not applicable.

\section{Authors' contributions}

IGA, CLM, MPZ, JL and MJCP have contributed to the conception and design of the study. All authors have acquired the data and have been involved in drafting the manuscript. The first draft of the manuscript was written by IGA, CLM, $J$ and MJCP. Contributions to the final version of the manuscript were made by all authors. The author(s) read and approved the final manuscript.

\section{Funding}

This research has been subsidized by the Valdecilla Health Research Institute (IDIVAL). Project awarded as the best project to be developed in Cantabria in the 19th call for research projects "Enfermería Valdecilla". The funders had no role in study design, data collection and analysis, decision to publish, or preparation of the manuscript.

\section{Availability of data and materials}

Data cannot be made publicly available in order to protect infant privacy. The data is available on request from the University of Cantabria Archive (http://repositorio.unican.es/) for researchers who meet the criteria for access to confidential data. Requests may be sent to the Ethics Committee (ceicc@idival.org) or Dr. Carolina Lechosa-Muñiz carolina.lechosa@scsalud.es).

\section{Declarations}

\section{Ethics approval and consent to participate}

This project was approved by the Ethics Committee for Clinical Research of Cantabria on July, 2017, reference number 2017.142. The parents signed an informed consent for participating in the study. The project was carried out according to the Spanish laws on biomedical research, the European Union regulations on the protection of natural persons with regard to the processing of personal data and the Declaration of Helsinki on ethical principles for medical research involving human subjects.

\section{Consent for publication}

Not applicable.

\section{Competing interests}

The authors declare no conflict of interest.

\section{Author details}

${ }^{1}$ Universidad de Cantabria - IDIVAL, Santander, Spain. ${ }^{2}$ CIBER Epidemiología y Salud Pública (CIBERESP), Madrid, Spain. ${ }^{3}$ Hospital Universitario Marqués de Valdecilla, Santander, Spain. ${ }^{4}$ Universidad de Cantabria, Santander, Spain.

Received: 18 March 2021 Accepted: 13 September 2021

Published online: 18 October 2021

\section{References}

1. McConnochie KM. Bronchiolitis: What's in the name? Am J Dis Child. 1983; 137(1):11-3. https://doi.org/10.1001/archpedi.1983.02140270007003.

2. Régnier SA, Huels J. Association between respiratory syncytial virus hospitalizations in infants and respiratory sequelae: systematic review and meta-analysis. Pediatr Infect Dis J. 2013;32(8):820-6. https://doi.org/10.1097/ INF.0b013e31829061e8.

3. Cody Meissner H. Viral bronchiolitis in children. N Engl J Med. 2016;374(1): 1791-4. https://doi.org/10.1056/NEJMra1413456.

4. Shi T, McAllister DA, O'Brien KL, Simoes EAF, Madhi SA, Gessner BD, et al. Global, regional, and national disease burden estimates of acute lower respiratory infections due to respiratory syncytial virus in young children in 2015: a systematic review and modelling study. Lancet. 2017;390(10098): 946-58. https://doi.org/10.1016/S0140-6736(17)30938-8.

5. Wu P, Hartert TV. Evidence for a causal relationship between respiratory syncytial virus infection and asthma. Expert Rev Anti-Infect Ther. 2011;9(9): 731-45. https://doi.org/10.1586/eri.11.92.

6. Lanari M, Prinelli F, Adorni F, Di Santo S, Vandini S, Silvestri M, et al. Risk factors for bronchiolitis hospitalization during the first year of life in a multicenter Italian birth cohort. Ital J Pediatr. 2015;41(1):40. https://doi.org/1 0.1186/s13052-015-0149-z.

7. Thorburn K. Pre-existing disease is associated with a significantly higher risk of death in severe respiratory syncytial virus infection. Arch Dis Child. 2009; 94(2):99-103. https://doi.org/10.1136/adc.2008.139188.

8. Carroll KN, Gebretsadik T, Griffin MR, Wu P, Dupont WD, Mitchel EF, et al. The increasing burden and risk factors for bronchiolitis-related medical visits in infants enrolled in a state healthcare insurance plan. Pediatrics. 2008; 122(1):58-64. https://doi.org/10.1542/peds.2007-2087.

9. Martinez FD, Wright AL, Holberg CJ, Morgan WJ, Taussig LM. Maternal age as a risk factor for wheezing lower respiratory illnesses in the first year of life. Am J Epidemiol. 1992;136(10):1258-68. https://doi.org/10.1093/ oxfordjournals.aje.a116434.

10. Koehoorn M, Karr CJ, Demers PA, Lencar C, Tamburic L, Brauer M. Descriptive epidemiological features of bronchiolitis in a population-based cohort. Pediatrics. 2008;122(6):1196-203. https://doi.org/10.1542/peds.2 007-2231.

11. Bradley JP, Bacharier LB, Bonfiglio J, Schechtman KB, Strunk R, Storch G, et al. Severity of respiratory syncytial virus bronchiolitis is affected by cigarette smoke exposure and atopy. Pediatrics. 2005;115(1):e7-14. https:// doi.org/10.1542/peds.2004-0059.

12. Nafstad P, Jaakkola J, Hagen J, Botten G, Kongerud J. Breastfeeding, maternal smoking and lower respiratory tract infections. Eur Respir J. 1996; 9(12):2623-9. https://doi.org/10.1183/09031936.96.09122623.

13. Cushing AH, Samet JM, Lambert WE, Skipper BJ, Hunt WC, Young SA, et al. Breastfeeding reduces risk of respiratory illness in infants. Am J Epidemiol. 1998;147(9):863-70. https://doi.org/10.1093/oxfordjournals.aje.a009540.

14. Bachrach VRG, Schwarz E, Bachrach LR. Breastfeeding and the risk of hospitalization for respiratory disease in infancy: a meta-analysis. Arch Pediatr Adolesc Med. 2003;157(3):237-43. https://doi.org/10.1001/archpedi.1 57.3.237. 
15. Dornelles CTL, Piva JP, Marostica PJC. Nutritional status, breastfeeding, and evolution of infants with acute viral bronchiolitis. J Health Popul Nutr. 2007; 25:336-43.

16. Chatzimichael A, Tsalkidis A, Cassimos D, Gardikis S, Tripsianis G, Deftereos S, et al. The role of breastfeeding and passive smoking on the development of severe bronchiolitis in infants. Minerva Pediatr. 2007:59(3):199-206.

17. World Health Assembly, 54. Global strategy for infant and young child feeding: the optimal duration of exclusive breastfeeding. World Health Organization. 2001. https://apps.who.int/iris/handle/10665/78801.

18. Theurich MA, Davanzo R, Busck-Rasmussen M, Díaz-Gómez NM, Brennan C,

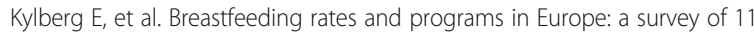
national breastfeeding committees and representatives. J Pediatr Gastroenterol Nutr. 2019;68(3):400-7. https://doi.org/10.1097/MPG. 0000000000002234.

19. $\mathrm{WHO} \mid$ Implementation of the Baby-friendly Hospital Initiative [Internet]. WHO. World Health Organization; [cited 2021 May 27]. Available from: http://www.who.int/elena/titles/bbc/implementation_bfhi/en/

20. Lechosa Muñiz C, Paz-Zulueta M, Cornejo del Río E, Mateo Sota S, Sáez de Adana M, Madrazo Pérez $M$, et al. Impact of maternal smoking on the onset of breastfeeding versus formula feeding: a cross-sectional study. Int J Environ Res Public Health. 2019;16(24):4888. https://doi.org/10.3390/ijerph1 6244888 .

21. World Health Organization (WHO). Indicators for assessing infant and young child feeding practices: conclusions of a consensus meeting held 6-8 November 2007 in Washington D.C., USA. Washington, D.C.: World Health Organization (WHO); 2008

22. Lechosa-Muniz C, Paz-Zulueta M, Sota SM, de Adana Herrero MS, del Rio EC, Llorca J, et al. Factors associated with duration of breastfeeding in Spain: a cohort study. Int Breastfeed J. 2020;15(1):79. https://doi.org/10.1186/s13006020-00324-6.

23. Harvey SM, Murphy VE, Gibson PG, Collison A, Robinson P, Sly PD, et al. Maternal asthma, breastfeeding, and respiratory outcomes in the first year of life. Pediatr Pulmonol. 2020;55(7):1690-6. https://doi.org/10.1002/ppul.24 756.

24. Azad MB, Vehling L, Lu Z, Dai D, Subbarao P, Becker AB, et al. Breastfeeding, maternal asthma and wheezing in the first year of life: a longitudinal birth cohort study. Eur Respir J. 2017;49(5):1602019. https://doi.org/10.1183/13993 003.02019-2016.

25. Lodge CJ, Tan DJ, Lau MXZ, Dai X, Tham R, Lowe AJ, et al. Breastfeeding and asthma and allergies: a systematic review and meta-analysis. Acta Paediatr. 2015;104(467):38-53. https://doi.org/10.1111/apa.13132.

26. Gdalevich M, Mimouni D, Mimouni M. Breast-feeding and the risk of bronchial asthma in childhood: a systematic review with meta-analysis of prospective studies. J Pediatr. 2001;139(2):261-6. https://doi.org/10.1067/ mpd.2001.117006.

27. Lanari M, Prinelli F, Adorni F, Di Santo S, Faldella G, Silvestri M, et al. Maternal milk protects infants against bronchiolitis during the first year of life. Results from an Italian cohort of newborns. Early Hum Dev. 2013;89: S51-7. https://doi.org/10.1016/S0378-3782(13)70016-1.

28. Dogaru CM, Nyffenegger D, Pescatore AM, Spycher BD, Kuehni CE. Breastfeeding and childhood asthma: systematic review and meta-analysis Am J Epidemiol. 2014;179(10):1153-67. https://doi.org/10.1093/aje/kwu072.

29. Davisse-Paturet C, Adel-Patient K, Divaret-Chauveau A, Pierson J, Lioret S, Cheminat $M$, et al. Breastfeeding status and duration and infections, hospitalizations for infections, and antibiotic use in the first two years of life in the ELFE cohort. Nutrients. 2019;11(7):1607. https://doi.org/10.3390/nu11 071607.

30. den Dekker HT, der Voort AMM S-V, WW J, Reiss IK, de Jongste JC, Duijts L. Breastfeeding and asthma outcomes at the age of 6 years: the generation $R$ study. Pediatr Allergy Immunol. 2016;27(5):486-92. https://doi.org/10.1111/ pai.12576.

31. Leung HWC, Hung L-L, Chan ALF, Mou C-H. Long-term use of antihypertensive agents and risk of breast cancer: a population-based casecontrol study. Cardiol Ther. 2015;4(1):65-76. https://doi.org/10.1007/s40119015-0035-1.

32. Nenna R, Cutrera R, Frassanito A, Alessandroni C, Nicolai A, Cangiano G, et al. Modifiable risk factors associated with bronchiolitis. Ther Adv Respir Dis. 2017;11(10):393-401. https://doi.org/10.1177/1753465817725722.

33. Dogaru CM, Strippoli M-PF, Spycher BD, Frey U, Beardsmore CS, Silverman $M$, et al. Breastfeeding and lung function at school age: does maternal asthma modify the effect? Am J Respir Crit Care Med. 2012;185(8):874-80. https://doi.org/10.1164/rccm.201108-14900C.

34. Guilbert TW, Stern DA, Morgan WJ, Martinez FD, Wright AL. Effect of breastfeeding on lung function in childhood and modulation by maternal asthma and atopy. Am J Respir Crit Care Med. 2007;176(9):843-8. https://doi. org/10.1164/rccm.200610-15070C.

35. Ogbuanu IU, Karmaus W, Arshad SH, Kurukulaaratchy RJ, Ewart S. Effect of breastfeeding duration on lung function at age 10 years: a prospective birth cohort study. Thorax. 2009;64(1):62-6. https://doi.org/10.1136/thx.2008.101 543.

36. Oddy WH, Halonen M, Martinez FD, Lohman IC, Stern DA, Kurzius-Spencer $\mathrm{M}$, et al. TGF-beta in human milk is associated with wheeze in infancy. J Allergy Clin Immunol. 2003;112(4):723-8. https://doi.org/10.1016/S0091-674 9(03)01941-9.

37. Munblit D, Peroni DG, Boix-Amorós A, Hsu PS, Land BV, Gay MC, et al. Human milk and allergic diseases: an unsolved puzzle. Nutrients. 2017;9(8): 894. https://doi.org/10.3390/nu9080894.

38. Pabst HF, Spady DW, Pilarski LM, Carson MM, Beeler JA, Krezolek MP. Differential modulation of the immune response by breast-or formulafeeding of infants. Acta Paediatr. 1997;86(12):1291-7. https://doi.org/1 0.1111/j.1651-2227.1997.tb14900.x.

39. Li C, Liu Y, Jiang Y, Xu N, Lei J. Immunomodulatory constituents of human breast milk and immunity from bronchiolitis. Ital J Pediatr. 2017;43(1):8. https://doi.org/10.1186/s13052-017-0326-3.

\section{Publisher's Note}

Springer Nature remains neutral with regard to jurisdictional claims in published maps and institutional affiliations.

\section{Ready to submit your research? Choose BMC and benefit from:}

- fast, convenient online submission

- thorough peer review by experienced researchers in your field

- rapid publication on acceptance

- support for research data, including large and complex data types

- gold Open Access which fosters wider collaboration and increased citations

- maximum visibility for your research: over $100 \mathrm{M}$ website views per year

At BMC, research is always in progress.

Learn more biomedcentral.com/submissions 